\title{
Ten years of prevalence and clinical laboratory features of HCMV infected children in a hospital of Jiangsu Province
}

\section{Wenwen Shang ( $D$ 1165309604@qq.com )}

the First Affiliated Hospital of Nanjing Medical University

Hong Zhao

the First Affiliated Hospital of Nanjing Medical University

\section{Guodong Rong}

the First Affiliated Hospital of Nanjing Medical University

Ting Xu

the First Affiliated Hospital of Nanjing Medical University

Lei Wu

the First Affiliated Hospital of Nanjing Medical University

\section{Peijun Huang}

the First Affiliated Hospital of Nanjing Medical University

\section{Fang Wang}

the First Affiliated Hospital of Nanjing Medical University

Jiexin Zhang

the First Affiliated Hospital of Nanjing Medical University

\section{Research article}

Keywords: HCMV, Children, Epidemiology, Clinical laboratory, Jiangsu Province

Posted Date: June 21st, 2019

DOI: https://doi.org/10.21203/rs.2.10513/v1

License: (c) (1) This work is licensed under a Creative Commons Attribution 4.0 International License. Read Full License 


\section{Abstract}

Background: Human cytomegalovirus (HCMV) is prevalent worldwide and causing lifelong infection. We conducted a retrospective study to determine the epidemiology and clinical laboratory characteristics of CMV infection in children in a hospital of Jiangsu Province. Methods: Totally 2600 urine specimens of infants and children hospitalized in general pediatric from 2009 to 2018 were collected followed by CMVDNA loads detection. Among them, clinical records and laboratory results of 971 infants aged 3-12 months were focused for further statistics analysis. Results: Urine CMV-DNA load test was intensively ordered in 2011 (17.76\%; 532/2996) for infants under 1 month but the rate continuously dropped ever since. In fact, infants under 1 month had the lowest detection sensitivity and children aged between 3 to 24 months had the highest positive rate. On the contrary, analysis of blood routine test showed that the absolute counts of peripheral leukocytes $(P=0.008)$, monocytes $(P=0.039)$, neutrophils $(P<0.001)$ and platelets $(\mathrm{P}=0.006)$ were significantly decreased in $\mathrm{CMV}+$ group compared with $\mathrm{CMV}$ - group. The percentages of neutrophils (NEUT\%) were decreased $(P<0.001)$ while the percentages of lymphocytes $(\mathrm{LYM} \%)$ were increased $(\mathrm{P}<0.001)$ by CMV infection. Moreover, NLR (neutrophil to lymphocyte ratio) $(P<0.01), M L R$ (monocyte to lymphocyte ratio) $(P=0.017)$ and $S$ II (systemic immune index) $(P=0.002)$ were also decreased in $\mathrm{CMV}+$ group. The hospitalization of cases in $\mathrm{CMV}+$ group was significantly longer than that of the CMV- group $(P=0.039)$, and the proportion of children with hospitalization stay longer than 2 weeks in $\mathrm{CMV}+$ group was higher, with significant difference $(P=0.006)$. Conclusion: $C M V$ survey has not drawn much attention in hospitalized infants and children, and the combined application of urine $\mathrm{CMV}$ detection and blood routine test should be benefit when assessing CMV infections.

\section{Background}

$\mathrm{HCMV}$ is a latent herpes virus and is highly prevalent in $30 \%$ to $100 \%$ populations throughout the world [ $1,2]$. CMV replicates silently in immune system and tissue cells after a series of immune responses and establishes lifelong persistence within the host [3], highly CMV viral loads were considered for lacking of control by the immune system and accounts for a considerable high frequency of reactivation [4]. Shedding CMV in urine and saliva appear to be the leading cause of CMV in primary infection, which is the major cause of severe congenital infection $[5,6]$. Thus, representative epidemiological data on the CMV infection of the infants and children may contribute useful information to infection prevention measures.

CMV infections are usually asymptomatic in immunocompetent hosts but has been implicated in a variety of diseases in healthy persons [ 7-10], it can also cause life-threatening complications once individual immune function is low or immune deficiency with an active infection [11,12]. The targets of CMV are all organs and tissue and has a profound impact on immune system, leading to the subversion of several types of immune cells and host immune functions $[13,14]$. Thus, imperfect establishment of immune system and immune function in infants and children are important reasons for the development of CMV. 
In this study, we retrospectively summarized CMV test order and positive rate according to both year and age. We also comprehensively investigate the laboratory features of peripheral immune system in hospitalized infants and children to evaluate last 10 year's clinic situation. Based on these representative epidemiological data in one general hospital of Jiangsu Province, we hope to arise public concern on CMV early intervention and control.

\section{Methods}

\section{Patients}

This retrospective study was carried out from January 2009 to December 2018 in the Pediatric General Ward of the First Affiliated Hospital of Nanjing Medical University, which was approved by the Ethical Committee. Patients who repeated two or more positive CMV-tests were considered as the same infective episode and only included once.

\section{Urinary CMV-DNA loads by RT-PCR}

We collected morning urine of all patients once hospitalization and detected the CMV-DNA loads by RTPCR (Applied Biosystems ${ }^{\circledR} 7500$, USA). All procedures are in accordance with manufacturer's instructions (Diagnostic kit for Quantification of Human Cytomegalovirus DNA, Daan). Higher than the threshold of 500 copies $/ \mathrm{mL}(\mathrm{c} / \mathrm{mL})$ was recognized as positive.

\section{Peripheral blood cells count by automatic blood cell analyzer}

Venous blood samples were collected from infants just be admitted to hospital who aged 3-12 months and tested for CMV-DNA during 2009 to 2018. All samples were measured within 2 hours according to the standard operating procedures of the Sysmex XS-800i (Sysmex Corporation, Japan) automatic hematology analyzer.

\section{Statistical analysis}

SPSS 20.0 software (IBM Corp, Armonk, NY, USA) was used to analyze all data. An

independent samples $t$-test was used for analyzing the differences between two groups. Data were presented as means \pm SEM, $P$ value less than 0.05 was considered significant.

\section{Results}




\section{Ten years survey of hospitalized children CMV epidemiology}

The number of children tested for CMV and the numbers of positive cases were showed in Fig. 1 by year. In total, $8.82 \%$ (2600/29475) hospitalized children were tested CMV-DNA loads by PCR in the past 10 year, of which $13.21 \%$ (273/2066), 15.82\% (335/2117), 17.76\% (532/2996), 15.33\% (460/3001), 8.78\% (269/3063), 6.66\% (220/3301), 3.91\% (127/3244), 5.68\% (171/3012), 3.25\% (93/2860) and 3.15\% (120/3815) in 2009 to 2018 respectively. However, the overall CMV positive rates of children from 2009 to 2018 were estimated to be $34.35 \%$ (893/2600), among 30.40\% (83/273), 32.24\% (108/335), 35.15\% (187/532), 28.48\% (131/460), 39.03\% (105/269), 44.55\% (98/220), 36.22\% (46/127), 39.18\% (67/171), $37.63 \%(35 / 93)$ and $27.50 \%(33 / 120)$ respectively. That is to say, the rates of CMV tests were getting lower and lower from 2011 to 2018, and were lowest in 2018. By contrast, the rates of CMV positive weren't decreased but increased slightly, with more than $30 \%$ in 8 out of 10 years. We further analyzed the epidemic of age distribution in 2600 children tested for CMV as shown in Fig.2, and found that the rates of CMV tests were $28.50 \%$ (741/2600) in infants aged under 1 months, $24.08 \%(626 / 2600)$ in infants aged 1-2 months, $11.50 \%(299 / 2600)$ in infants aged 3-4 months, $8.08 \%(210 / 2600)$ in infants aged 5-6 months, $5.04 \%(131 / 2600)$ in infants aged 7-8 months, 2.88\% (75/2600) in infants aged 9-10 months, $12.23 \%$ (318/2600) in infants aged 11-12 months, 3.08\% (80/2600) in infants aged 13-24 months, $1.46 \%$ $(38 / 2600)$ in infants aged $25-36$ months and $3.15 \%(82 / 2600)$ in infants older than 36 months. Whereas, the positive tests were found in $6.21 \%(46 / 741), 29.07 \%$ (182/626), 53.51\% (160/299), 62.86\% (132/210), $59.54 \%$ (78/131), 61.33\% (46/75), 55.35\% (176/318), 68.75\% (55/80), 26.32\% (10/38) and $9.76 \%(8 / 82)$ respectively. In a word, the rates of CMV tests were decreased with age while the positive rates of CMV were increased in infants aged 1-24 months, result in the peaked detection rates of CMV in infants under 1 months with the lowest CMV positive rates, and the positive rates of CMV were all higher than $50 \%$ in infants aged 3-12 months. Therefore, these data indicated that CMV infection has not been taken seriously in children of Chinese hospitals.

\section{The characteristics of peripheral immune status in CMV-infected infants}

Due to CMV infection was most prevalent in infants aged 3-12 months and the distribution characteristics of peripheral blood cells in young children. We thus recruited all 971 patients aged 3-12 months in this study to investigate the distribution features of peripheral blood cells in infants once admitted to hospital, among which 562 patients were CMV+ group, 409 patients were CMV- group. As shown in Fig. 3 , the absolute counts of peripheral leukocytes $\left(8.885 \pm 0.1458 \times 10^{9}\right.$ vs. $9.517 \pm 0.1928 \times 10^{9}$; $P=0.008)$, monocytes $\left(0.6931 \pm 0.01573 \times 10^{9}\right.$ vs. $\left.0.7459 \pm 0.02074 \times 10^{9} ; P=0.039\right)$, neutrophils $\left(2.57 \pm 0.07737 \times 10^{9}\right.$ vs. $\left.3.079 \pm 0.1044 \times 10^{9} ; P<0.001\right)$ and platelets $\left(340.2 \pm 5.24 \times 10^{9}\right.$ vs. $363.1 \pm 6.595 \times 10^{9}$; $P=0.006)$ were significantly decreased in $\mathrm{CMV}+$ group compared with $\mathrm{CMV}$ - group. Besides, the 
percentages of neutrophils (NEUT\%) were also decreased ( $28.76 \pm 0.6307$ vs. $32.12 \pm 0.7639 ; P<0.001)$, while the percentages of lymphocytes (LYM\%) were increased $(60.99 \pm 0.6238 v$ vs. $57.5 \pm 0.7729 ; P<0.001)$ in CMV+ group. Given the disordered distribution of peripheral blood cells in CMV infected infants, we thus continuously explored the features of several novel systemic inflammatory indicators including NLR (neutrophil to lymphocyte ratio), MLR (monocyte to lymphocyte ratio), PLR (platelet to lymphocyte ratio) and SII (systemic immune index $=$ NLR $\times$ platelet), which could reflect the systemic inflammatory and immune responses accurately for combining the three types of circulating immune-inflammatory cells. As shown in Fig.4, we found compared with CMV- group, NLR $(0.6121 \pm 0.03098$ vs. $0.7394 \pm 0.03872$; $P=0.010), \operatorname{MLR}(0.1455 \pm 0.004372$ vs. $0.1625 \pm 0.005716 ; P=0.017)$ and SII $(205.2 \pm 9.549$ vs. $255.9 \pm 13.76$; $P=0.002)$ were also decreased in CMV+ group, although PLR (75.55 \pm 1.97 vs. $78.97 \pm 2.149 ; P>0.05)$ showed no significant difference between two groups. Thus, these data implied the imbalanced peripheral blood cells distribution which may result in the disordered peripheral immune of infants with CMV infection, and the combination of blood routine test and systemic inflammatory indicators may be responsible for the identification of CMV.

\section{Extended hospitalization duration of CMV-infected infants}

As follow-up extended, we calculated their days of hospitalization respectively and found that CMV+ group had prolonged hospitalization cycle $(9.12 \pm 2.88 \mathrm{vs}$. 8.28 $\pm 1.79, P=0.039)$, and the proportion of children with hospitalization stay longer than 2 weeks in CMV+ group was higher than that of CMVgroup, with significant difference $(14.44 \%$ vs. $1.56 \%, P=0.006)$. These results indicated that CMV infected infants required superior nursing and longer recovery.

\section{Discussion}

CMV becomes a public health event in developing countries. The seroprevalence of CMV in Chinese pregnant women is over $90 \%$ and $0.03 \%-2.0 \%$ in newborns leading to high morbidity and mortality in newborns. Nevertheless, awareness and surveillance of CMV in infants and children have remained unsubstantial in most Chinese hospitals although CMV test is one of the laboratory routine test after initial admission [ 15-17]. In this study, we present data from a large cohort of infants and children with CMV infection in the past 10 years. To our knowledge, this is the first prospective investigation about CMV-DNA loads in infants and children in Jiangsu Province. The data revealed that CMV tests were being ignored for the rates of CMV test were $17.75 \%$ to $3.15 \%$ from 2011 to 2018 , but the positive rates were more than $30 \%$. And the age distribution characteristics showed that attention has been paid to congenital CMV infection with the most CMV-DNA test rate of infants under 1 months, however, the positive rate was far beyond $50 \%$ in infants aged 3-24 months. In view of the low detection rate and high incidence of CMV in China, routine laboratory monitor and effective treatment strategies should be emphasized and improved. 
CMV reactivates and spreads to organs as well as immune cells including lymphocytes, monocytes and neutrophils to accomplish dissemination [18-20], when blood routine test result can reflect the systemic inflammatory and immune responses [21-23]. In this study, we collected blood routine test results of 971 hospitalized infants aged from 3 to 12 months and found that the absolute counts of peripheral leukocytes, monocytes, neutrophils and platelets were significantly decreased in CMV+ group. As previously reported, $\mathrm{CMV}$ is associated with pancytopenia: 1 ) it downregulates granulocyte colony stimulating factor (G-CSF) or induces production of inhibitory cytokines as Interleukin-6 (IL-6) [24-26] and Interleukin-8 (IL-8) [ 27, 28] to suppress of hematopoiesis; 2 ) it directly infects monocytes and hematopoietic stem or progenitor cells [29]; 3) it modulates host immune responses via gp34 and gp68 to promote viral survival and dissemination for humoral immunity escape or by decreasing presentation

function of $\mathrm{CD}^{+}{ }^{+} \mathrm{T}$ cells $\mathrm{CD} 8^{+} \mathrm{T}$ cells to disturb cellular immunity [ 30-33]; 4) it induces differentiation and migration of infected monocytes [ $19,34,35]$ and develop chemokines to recruit neutrophils [36-38]. In addition, several novel systemic inflammatory indicators, known as NLR, MLR, PLR and SII, are more accurate for combining circulating immune-inflammatory cells $[39,40]$. It was suggested that NLR, MLR, PLR and SII have an effective and powerful connection with infectious diseases. We thus further discussed the features of these four systemic inflammatory indicators according to the blood routine results, and found the levels of NLR, MLR and SIl were all decreased in CMV+ group. These data indicated the imbalanced peripheral blood cells distribution may result in the disordered peripheral immune and lead to prolong hospital stay of CMV-infected infants, and the combination of these peripheral blood cells and systemic inflammatory indicators may be a set of crucial laboratory markers in recognition of CMV infection. Detailed reference ranges of these parameters as to infants are needed to be determined by statistical analysis of massive and rigorous data.

\section{Conclusions}

In summary, this study shed a light on epidemiology and clinical indicators of infants with CMV infection and hope to raise enough attention to $\mathrm{CMV}$ pathogenesis and prognosis.

\section{Abbreviations}

HCMV: Human cytomegalovirus; NLR: neutrophil to lymphocyte ratio; PLR: platelet to lymphocyte ratio; MLR: monocyte to lymphocyte ratio; SII: systemic immune index.

\section{Declarations}

\section{Ethics approval and consent to participate}

This study was approved by the First Affiliated Hospital of Nanjing Medical University and signed informed consent was obtained from parents or legal guardians of children under 18 years old. 


\section{Consent to publish}

Not applicable.

\section{Availability of data and materials}

Not applicable.

\section{Competing interests}

The authors declare that they have no competing interests.

\section{Funding}

This study was supported by the Natural Science Youth Foundation of China (NO. 81501817), the National Natural Science Foundation of China (NO. 81772779), the Natural Science Youth Foundation of Jiangsu Province (NO. BK20151029), "Professionals from Six-Pronged Top-Talent Program" of Jiangsu Province (No. LGY2017068), "The Six Top Talent Project” of Jiangsu Province (NO. 2015-WSN-034), Jiangsu Province's Key Provincial Talents Program (NO. ZDRCA2016003) and Key Laboratory for Medicine of Jiangsu Province of China (NO. ZDXKB2016005), which funds the design of the study, analysis, and interpretation of data and in writing the manuscript.

\section{Author contributions}

WS, $\mathrm{HZ}$ and GR contributed equally to this work. WS collected the data, analyzed the data and wrote the paper; $\mathrm{HZ}$ and GR collected the data; TX and LW wrote the paper; PH and FW supported the clinical data of these patients; JZ designed and supervised the study. All authors have read and approved the final manuscript.

\section{Acknowledgements}

Not applicable.

\section{References}

1. Kenneson A, Cannon MJ. Review and meta-analysis of the epidemiology of congenital cytomegalovirus (CMV) infection. Rev Med Virol 2007;17(4):253-76. 
2. Bate SL, Dollard SC, Cannon MJ. Cytomegalovirus seroprevalence in the United States: the national health and nutrition examination surveys, 1988-2004. Clin Infect Dis 2010;50(11):1439-47.

3. Varani S, Landini MP. Cytomegalovirus-induced immunopathology and its clinical consequences. Herpesviridae 2011;2(1):6.

4. Parry HM, Zuo J, Frumento G, Mirajkar N, Inman C, Edwards E, et al. Cytomegalovirus viral load within blood increases markedly in healthy people over the age of 70 years. Immun Ageing 2016;13:1.

5. Cannon MJ, Hyde TB, Schmid DS. Review of cytomegalovirus shedding in bodily fluids and relevance to congenital cytomegalovirus infection. Rev Med Virol 2011;21(4):240-55.

6. Riga M, Korres G, Chouridis P, Naxakis S, Danielides V. Congenital cytomegalovirus infection inducing non-congenital sensorineural hearing loss during childhood; a systematic review. Int J Pediatr Otorhinolaryngol 2018;115:156-164.

7. Savva GM, Pachnio A, Kaul B, Morgan K, Huppert FA, Brayne C, et al. Cytomegalovirus infection is associated with increased mortality in the older population. Aging Cell 2013;12(3):381-7.

8. Hui J, Qu YY, Tang N, Liu YM, Zhong H, Wang LM, et al. Association of cytomegalovirus infection with hypertension risk: a meta-analysis. Wien Klin Wochenschr 2016;128(15-16):586-91.

9. Wall NA, Chue CD, Edwards NC, Pankhurst T, Harper L, Steeds RP, et al. Cytomegalovirus seropositivity is associated with increased arterial stiffness in patients with chronic kidney disease. PLoS One 2013;8(2):e55686.

10. Siegmund B. Cytomegalovirus infection associated with inflammatory bowel disease. Lancet Gastroenterol Hepatol 2017;2(5):369-376.

11. Rafailidis PI, Mourtzoukou EG, Varbobitis IC, Falagas ME. Severe cytomegalovirus infection in apparently immunocompetent patients: a systematic review. Virol J 2008;5:47.

12. Zhang J, Chen X, Rong G, Xu T, Zhao H, Chen D, et al. Peripheral blood lymphocyte responses to cytomegalovirus seropositivity after allogeneic-hematopoietic stem cell transplantation. Onco Targets Ther 2018;11:5143-5150.

13. Pawelec G. Immunosenenescence: role of cytomegalovirus. Exp Gerontol 2014;54:1-5.

14. Chidrawar S, Khan N, Wei W, McLarnon A, Smith N, Nayak L, et al. Cytomegalovirus-seropositivity has a profound influence on the magnitude of major lymphoid subsets within healthy individuals. Clin Exp Immunol 2009;155(3):423-32.

15. Jin Q, Su J, Wu S. Cytomegalovirus Infection among Pregnant Women in Beijing: Seroepidemiological Survey and Intrauterine Transmissions. J Microbiol Biotechnol 2017;27(5):1005-1009. 
16. Zhang S, Hu L, Chen J, Xu B, Zhou YH, Hu Y. Cytomegalovirus seroprevalence in pregnant women and association with adverse pregnancy/neonatal outcomes in Jiangsu Province, China. PLoS One 2014;9(9):e107645.

17. Wang S, Wang T, Zhang W, Liu X, Wang X, Wang H, et al. Cohort study on maternal cytomegalovirus seroprevalence and prevalence and clinical manifestations of congenital infection in China. Medicine (Baltimore) 2017;96(5):e6007.

18. Rice GP, Schrier RD, Oldstone MB. Cytomegalovirus infects human lymphocytes and monocytes: virus expression is restricted to immediate-early gene products. Proc Natl Acad Sci U S A 1984;81(19):6134-8.

19. Frascaroli G, Varani S, Moepps B, Sinzger C, Landini MP, Mertens T. Human cytomegalovirus subverts the functions of monocytes, impairing chemokine-mediated migration and leukocyte recruitment. J Virol 2006;80(15):7578-89.

20. Varani S, Frascaroli G, Landini MP, Soderberg-Naucler C. Human cytomegalovirus targets different subsets of antigen-presenting cells with pathological consequences for host immunity: implications for immunosuppression, chronic inflammation and autoimmunity. Rev Med Virol 2009;19(3):131-45.

21. Jenne CN, Kubes P. Platelets in inflammation and infection. Platelets 2015;26(4):286-92.

22. Grivennikov SI, Greten FR, Karin M. Immunity, inflammation, and cancer. Cell 2010;140(6):883-99.

23. Petersone L, Edner NM, Ovcinnikovs V, Heuts F, Ross EM, Ntavli E, et al. T Cell/B Cell Collaboration and Autoimmunity: An Intimate Relationship. Front Immunol 2018;9:1941.

24. Dilloo D, Josting A, Burdach S. CMV infection modulates interleukin-6 production in human bone marrow stroma cells. Bone Marrow Transplant 1991;7 Suppl 2:152.

25. Geist LJ, Dai LY. Cytomegalovirus modulates interleukin-6 gene expression. Transplantation 1996;62(5):653-8.

26. Bennett JM, Glaser R, Malarkey WB, Beversdorf DQ, Peng J, Kiecolt-Glaser JK. Inflammation and reactivation of latent herpesviruses in older adults. Brain Behav Immun 2012;26(5):739-46.

27. Murayama T, Kuno K, Jisaki F, Obuchi M, Sakamuro D, Furukawa T, et al. Enhancement human cytomegalovirus replication in a human lung fibroblast cell line by interleukin-8. J Virol 1994;68(11):75825 .

28. Murayama T, Mukaida N, Khabar KS, Matsushima K. Potential involvement of IL-8 in the pathogenesis of human cytomegalovirus infection. J Leukoc Biol 1998;64(1):62-7.

29. Almeida-Porada GD, Ascensao JL. Cytomegalovirus as a cause of pancytopenia. Leuk Lymphoma 1996;21(3-4):217-23. 
30. Huygens A, Lecomte S, Tackoen M, Olislagers V, Delmarcelle $\mathrm{Y}$, Burny $\mathrm{W}$, et al. Functional Exhaustion Limits CD4+ and CD8+ T-Cell Responses to Congenital Cytomegalovirus Infection. J Infect Dis 2015;212(3):484-94.

31. Jackson SE, Sedikides GX, Mason GM, Okecha G, Wills MR. Human Cytomegalovirus (HCMV)-Specific CD4(+) T Cells Are Polyfunctional and Can Respond to HCMV-Infected Dendritic Cells In Vitro. J Virol 2017;91(6).

32. Vieira Braga FA, Hertoghs KM, van Lier RA, van Gisbergen KP. Molecular characterization of HCMVspecific immune responses: Parallels between CD8(+) T cells, CD4(+) T cells, and NK cells. Eur J Immunol 2015;45(9):2433-45.

33. Wunsch M, Zhang W, Hanson J, Caspell R, Karulin AY, Recks MS, et al. Characterization of the HCMVSpecific CD4 T Cell Responses that Are Associated with Protective Immunity. Viruses 2015;7(8):4414-37.

34. Stevenson EV, Collins-McMillen D, Kim JH, Cieply SJ, Bentz GL, Yurochko AD. HCMV reprogramming of infected monocyte survival and differentiation: a Goldilocks phenomenon. Viruses 2014;6(2):782-807.

35. Smith MS, Bentz GL, Alexander JS, Yurochko AD. Human cytomegalovirus induces monocyte differentiation and migration as a strategy for dissemination and persistence. J Virol 2004;78(9):4444-53.

36. Heo J, Dogra P, Masi TJ, Pitt EA, de Kruijf P, Smit MJ, et al. Novel Human Cytomegalovirus Viral Chemokines, vCXCL-1s, Display Functional Selectivity for Neutrophil Signaling and Function. J Immunol 2015;195(1):227-36.

37. Pocock JM, Storisteanu DML, Reeves MB, Juss JK, Wills MR, Cowburn AS, et al. Human Cytomegalovirus Delays Neutrophil Apoptosis and Stimulates the Release of a Prosurvival Secretome. Front Immunol 2017;8:1185.

38. Yamin R, Lecker LSM, Weisblum Y, Vitenshtein A, Le-Trilling VTK, Wolf DG, et al. HCMV vCXCL1 Binds Several Chemokine Receptors and Preferentially Attracts Neutrophils over NK Cells by Interacting with CXCR2. Cell Rep 2016;15(7):1542-1553.

39. Taylan M, Demir M, Kaya H, Selimoglu Sen H, Abakay O, Carkanat Al, et al. Alterations of the neutrophil-lymphocyte ratio during the period of stable and acute exacerbation of chronic obstructive pulmonary disease patients. Clin Respir J 2017;11(3):311-317.

40. Paliogiannis P, Fois AG, Sotgia S, Mangoni AA, Zinellu E, Pirina P, et al. Neutrophil to lymphocyte ratio and clinical outcomes in COPD: recent evidence and future perspectives. Eur Respir Rev 2018;27(147).

\section{Figures}



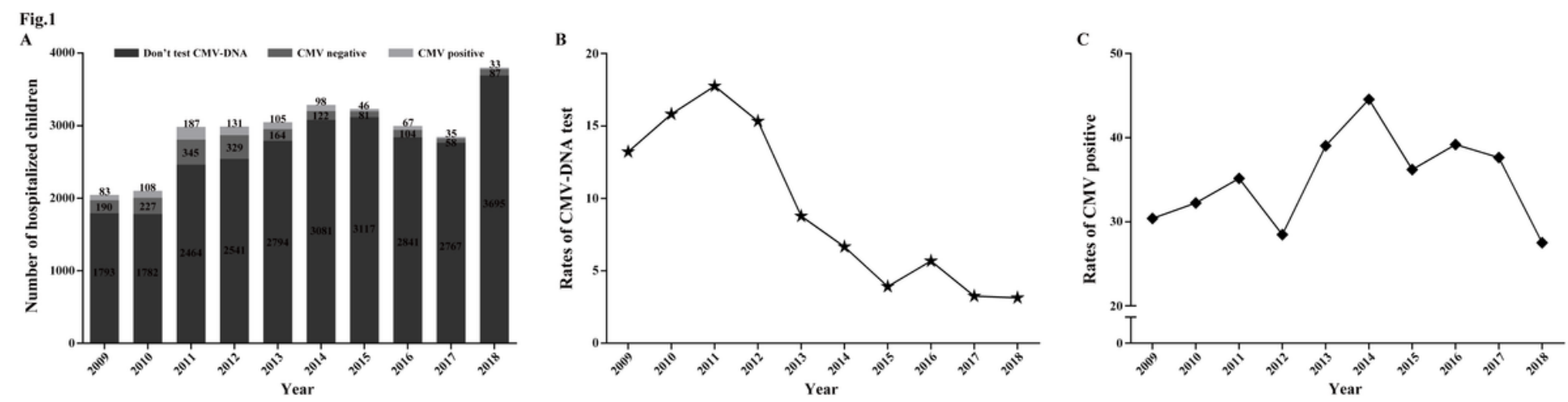

Figure 1

Number and rates of CMV tests and CMV positive by year
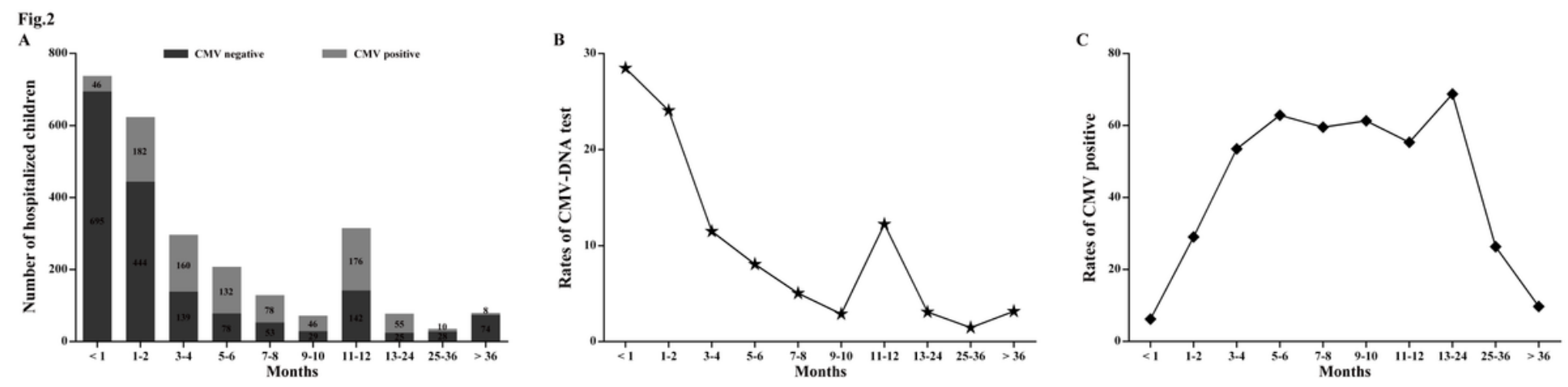

Figure 2

Number and rates of CMV tests and CMV positive by age
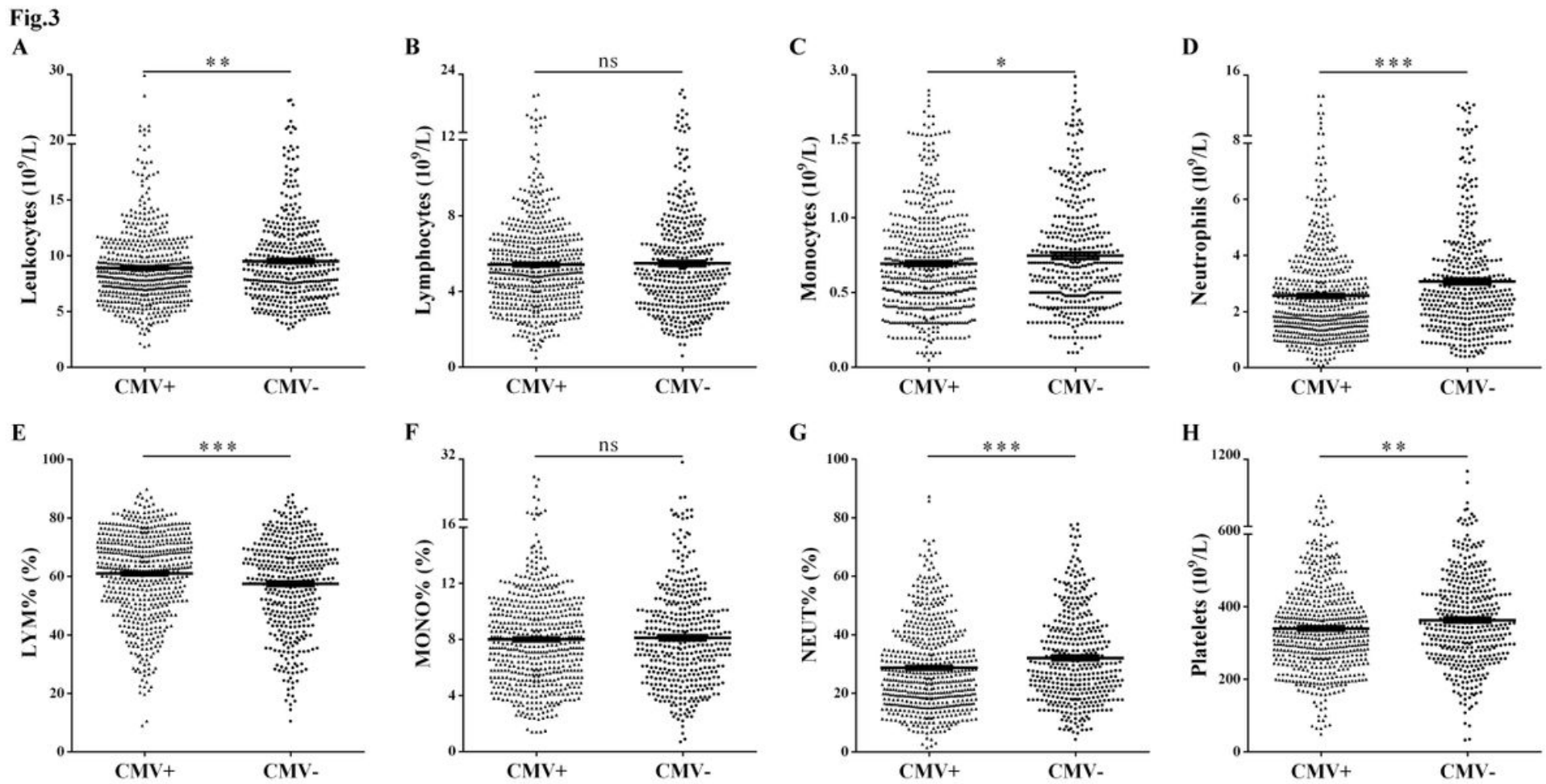
Figure 3

Distribution features of peripheral blood cells in infants with CMV infection $(A, B, C, D, H)$ The absolute counts of leukocytes, lymphocytes, monocytes, neutrophils and platelets in CMV+ group $(n=562)$ compared with CMV- group ( $n=409) ;(E, F, G)$ The percentages of lymphocytes (LYM\%), monocytes (MONO\%) and neutrophils (NEUT\%) in CMV+ group ( $n=562)$ compared with CMV-group $(n=409)$. Data was presented as means \pm SEM. ${ }^{*} P<0.05,{ }^{*} \mathrm{P}<0.01,{ }^{*} * \mathrm{P}<0.001$.

\section{Fig.4}

A

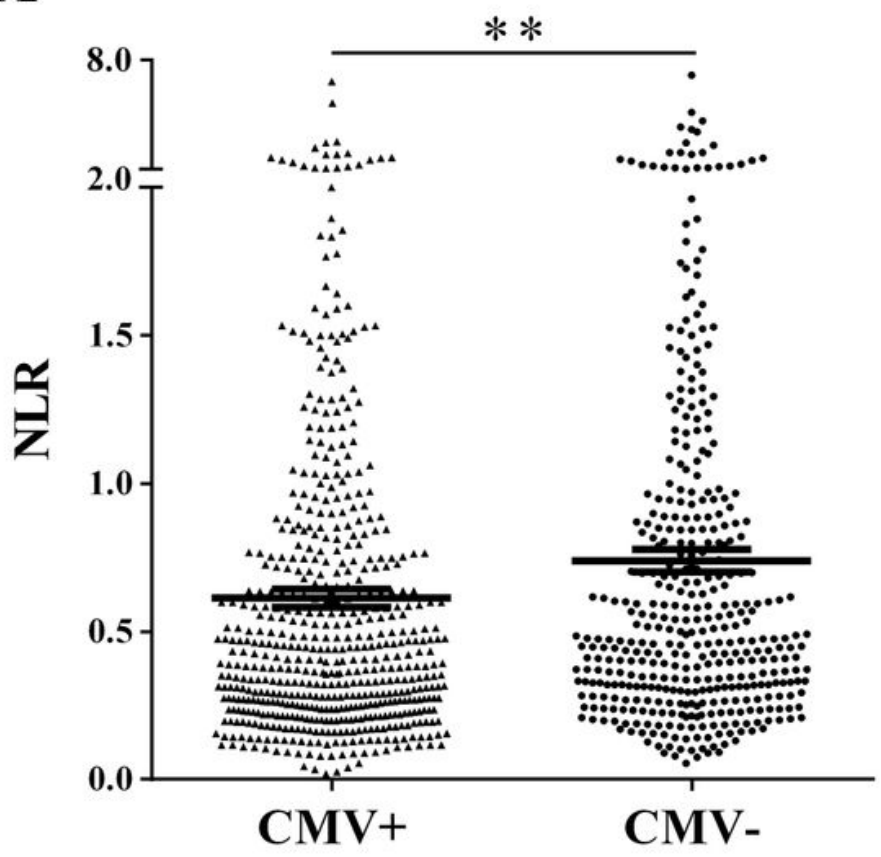

C

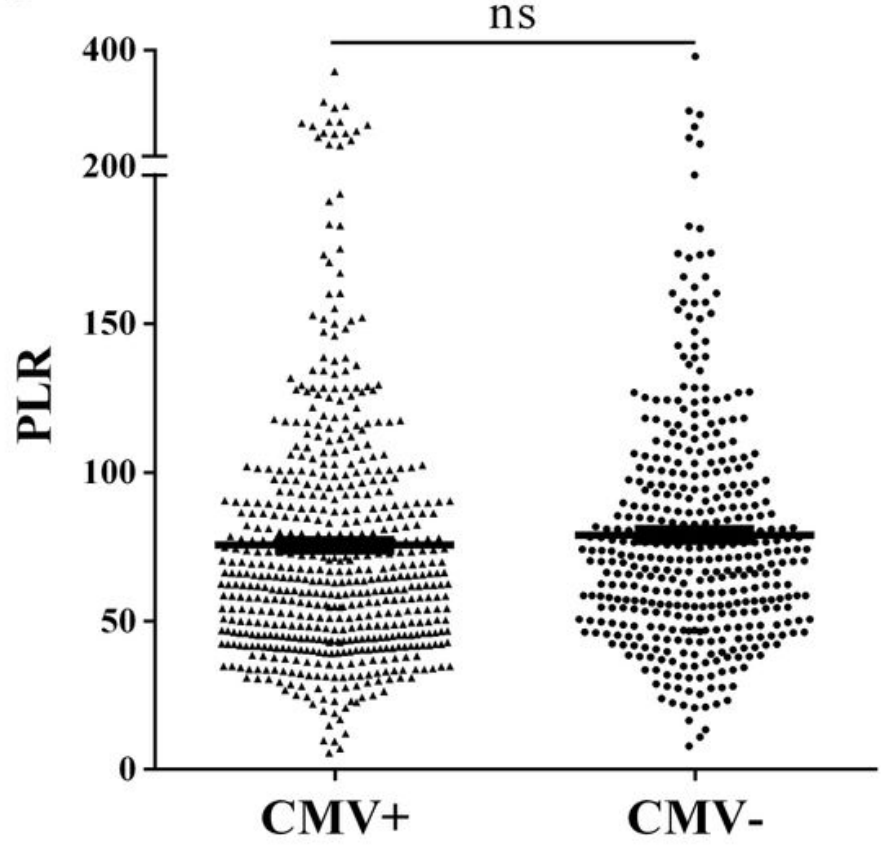

B

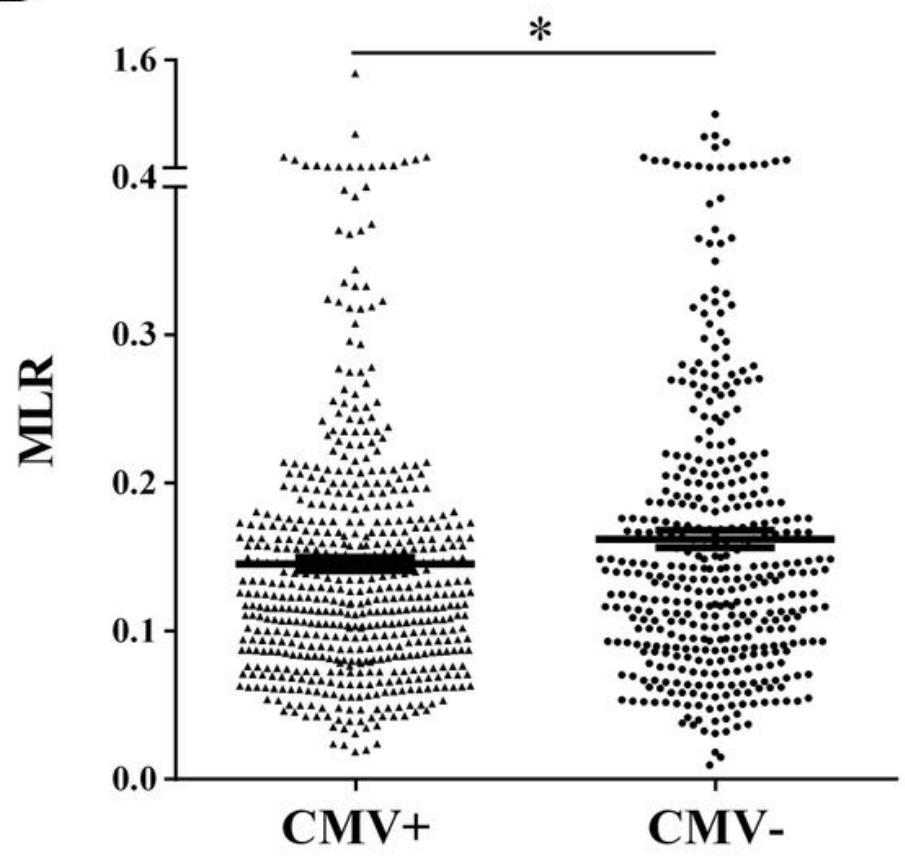

D

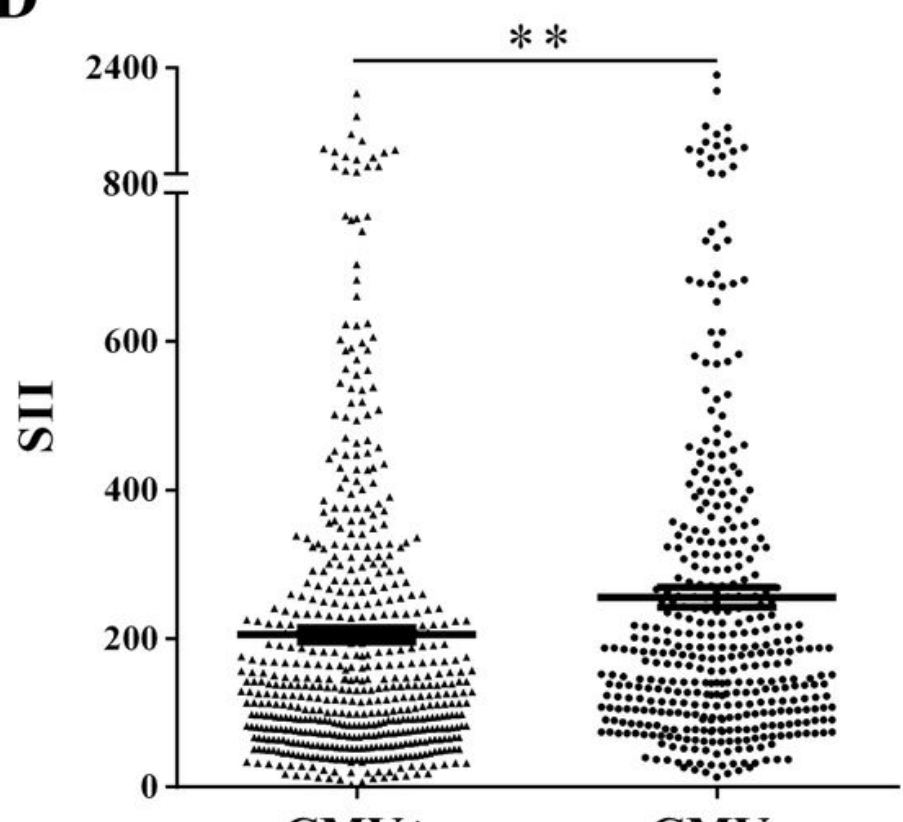


The levels of systemic inflammatory indicators in infants with CMV infection (A, B, C, D) The levels of NLR (neutrophil to lymphocyte ratio), LMR (monocyte to lymphocyte ratio), PLR (platelet to lymphocyte ratio) and SII (systemic immune index $=$ NLR $\times$ platelet) in CMV+ group $(n=562)$ compared with CMVgroup $(n=409)$. Data was presented as means \pm SEM. $* P<0.05, * * P<0.01$. 